\title{
A Contraction Based Solution for the Improvement of Fish Ladder Attraction Flow
}

\author{
Kristian Angele ${ }^{1, ~ *}$, Patrik Andreasson ${ }^{1,2}$, Ake Forssen ${ }^{1}$, David Aldven ${ }^{1}$, Gustav Hellstrom ${ }^{3}$, \\ Kjell Leonardsson ${ }^{3}$ \\ ${ }^{1}$ Vattenfall AB, Research and Development, Laboratories, Älvkarleby, Sweden \\ ${ }^{2}$ Divison of Fluid and Experimental Mechanics, Lulea University of Technology, Lulea, Sweden \\ ${ }^{3}$ Department of Wildlife, Fish and Environmental Studies, Umea, Swedish University of Agricultural Sciences, Uppsala, Sweden
}

Email address:

kristian.angele@vattenfall.com (K. Angele), patrik.andreasson@vattenfall.com (P. Andreasson), ake.forssen@vattenfall.com (A. Forssén), david.aldven@vattenfall.com (D. Aldvén), gustav.hellstrom@slu.se (G. Hellstrom), kjell.leonardsson@slu.se (K. Leonardsson)

${ }^{*}$ Corresponding author

\section{To cite this article:}

Kristian Angele, Patrik Andreasson, Ake Forssen, David Aldven, Gustav Hellstrom, Kjell Leonardsson. A Contraction Based Solution for the Improvement of Fish Ladder Attraction Flow. American Journal of Water Science and Engineering. Vol. 7, No. 2, 2021 , pp. 57-71. doi: 10.11648/j.ajwse.20210702.14

Received: April 22, 2021; Accepted: May 24, 2021; Published: June 4, 2021

\begin{abstract}
A new, potentially cost efficient, concept for improving the attraction flow to a fish ladder has been investigated in a case study. For the upstream migrating Atlantic salmon to reach the fish ladder and by-pass the case study hydropower plant, it must be able to localize the attraction flow where it enters the main flow from the tailrace of the hydropower plant in the so-called confluence area. Here the comparatively small and limited attraction flow from the old river channel must be improved in order to be able compete with the substantially larger main flow. The objective of the present study is to investigate the feasibility of a new concept for further improvement of the attraction flow using guiding walls forming a contraction channel. Field measurements were performed tracing tagged fish in the confluence area downstream of the case study hydropower plant in order to understand the movement pattern of the fish. Based on the results, and results from bathymetry measurements in the same area, a physical scale model was constructed where it was experimentally demonstrated that it is hydraulically feasible to construct guiding walls, forming a contraction, which accelerate the attraction flow and generate a concentrated turbulent jet with a higher velocity, while keeping the flow rate unchanged. The attraction flow penetrates about half-way (70 m) into the main flow and reaches the position where most fish are positioned according to fish position measurements and therefore potentially has a good ability to attract upstream migrating fish. There is no negative impact on the water level in the confluence area and thereby not on electricity production. It was shown that the results can be scaled up to prototype conditions and the strategy can presumably be generalized to similar flow situations, existing at other hydropower plants, allowing for improved upstream fish migration in coexistence with a sound hydropower production.
\end{abstract}

Keywords: Attraction Flow, Salmon, Fish Migration, Acoustic Telemetry, Physical Scale Model Test, Hydropower

\section{Introduction}

Biodiversity is one of the top priorities on the current global political agenda as is that of global warming, which requires fossil free and stable base-load energy production and storage capacity, i.e. hydropower with dams and their associated reservoirs. The balance between these two, sometimes contradicting, areas of interest needs to be addressed carefully. These issues are considered within the
EU Water Framework Directive (2000/60/EC) and serves as the driving force for the present study.

\subsection{Upstream Migrating Fish Passage and Fish Ways}

The life cycle of anadromous migrating fish contains both upstream and downstream migration in rivers. A few years after birth, migrating fish swim downstream the river to the sea to where they eat and grow. Mature fish migrate back upstream in the river to the place where they were born in 
order to spawn. Hydropower plants and the associated dams constitute a physical obstacle for migrating fish which must be passed. Fish passage is a multidisciplinary field within eco-hydraulics where experts in both fish biology and fluid physics work collectively. There are different ways to realize fish passage, e.g. nature-like fishways, such as bypass channels, or technical, constructed fishways.

Recommendations for fish passage exist in several handbooks, e.g. USFWS [39], BAW/BfG [20], DVWK [17], Armstrong et al. [5] and Calles et al. (2013). The downstream and upstream migration are addressed in different ways. The focus here is on upstream migration.

There are essentially eight different types of designs for constructed fishways for upstream migration; spillway or steps, pool and weir fishway, vertical slot fishway, Denil (steep pass) fishway, fish elevator, fish sluice (fish lock), fish pump and eel ladder, Calles [11].

\subsection{Attraction Flow to Constructed Fish Ways}

Due to the high flow rate through large scale hydropower plants and the comparatively low flow rate in a fish passage, the latter sometimes needs to be complemented with a larger flow rate to create an attraction flow which the fish have a chance to localize. For that to happen the attraction flow should cover a certain area or reach a certain distance. The momentum, i.e. the product of the flow rate and velocity of the attraction flow governs its penetration into the competing main flow.

The basic considerations and design criteria for upstream migration are which species should pass, how easy it was to pass before the hydropower plant was built, what time of year the migration occurs, what the swimming capacity of the fish is, if they have a behavior which facilitates passage and finally which predators that are present, Calles [11].

Fish are attracted by different factors, e.g. sound, light conditions, water temperature and the velocity of the streaming water. Velocity gradients, i.e. differences in the velocity field, and the associated turbulence and large scale vortical structures, are also important factors.

The velocity in the attraction flow must be high enough in order to attract the fish, but it should not be higher than the swimming ability of the fish. Prolonged swimming speed of Atlantic salmon (Salmo salar) and anadromous brown trout (Salmo trutta) ranges between about $2 \mathrm{~m} / \mathrm{s}$ and $5 \mathrm{~m} / \mathrm{s}$, depending on water temperature and the length of the fish, see Calles [11], Castro-Santos [14], Peake [33], Larinier [25], Larinier [26], Katopidis [22] and Beach [8].

\subsection{Scope and Goal of the Present Study}

The aim of the present study was to improve the attraction flow from the old river channel, see Figure 1, i.e. increase the velocity and penetration of the attraction flow into the main flow in the confluence area and thereby increase the probability for the fish to locate the attraction flow and improve passage efficiency for migrating fish.

One commonly suggested solution is to simply increase the flow rate, which will have a negative impact on the old river channel as potential biotope, see Angele [2], but also on the production of the hydropower plant.

A fluid mechanical alternative originating in the continuity equation or conservation of mass, is to keep the flow rate unchanged and decrease the area where the attraction flow is introduced into the confluence area and thereby increase the velocity. The latter is the basic strategy investigated here, practically implemented by designing guiding walls, which will concentrate the attraction flow.

The primary goal was to generate an attraction flow jet with a relatively high velocity, which can compete with the velocity in the main flow from the tailrace channel at the nominal flow rates and serve as an efficient attraction for the fish in the confluence area. Turbulent jets have all the attractive features described above, i.e. velocity, turbulence, velocity gradients and are therefore optimal for the purpose.

A preferred water velocity between $2 \mathrm{~m} / \mathrm{s}$ and $3 \mathrm{~m} / \mathrm{s}$ was set as a target to provide both a high enough velocity to compete with the water velocity of the tailrace, and to enable fish to migrate.

A secondary aim was to have a rather high Froude number $\left(F r_{A}\right)$, see (2), at the outlet of the attraction flow channel, based on the local hydraulic parameters of water velocity and depth, in order to get a flow which starts to become streaming, i.e. initiating sound and turbulent features similar to when approaching a rapid. However, $F r_{A}$ should preferably be less than unity to avoid that a supercritical flow develops $\left(F r_{A}>1\right)$, causing excessive dissipation of the jet once a hydraulic jump develops downstream.

On top of the main considerations above regarding the optimization of the attraction flow with regard to the fish preferences, also the hydraulic loads (i.e. the pressure loads on a guiding wall due the difference in water level on its two sides and the dynamic pressure from the moving water) was required to be addressed simultaneously.

The potential risk for erosion of the river bottom also required attention when increasing the velocity of the attraction flow, which also leads to higher shear forces. It is desired to have a high enough velocity at the outlet of the attraction flow channel and at the same time avoid too high velocities at as many off-design flow conditions as possible. This constitutes a delicate optimization problem addressed in an empirical manner in the physical scale model part of the present experimental study.

A final practical consideration was to keep the length of the guiding walls as short as possible to minimize the distance with high velocity that the fish need to overcome but also in order to keep construction time and associated costs down.

Conducting numerical simulations via computational fluid dynamics (CFD) with a free water surface requires transient two-phase flow simulations, which are complex and associated with long calculation times and large uncertainties. To resolve the confluence area is practically impossible. However, as a rough design tool or in a detailed design of the local region around the entrance of the attraction flow channel CFD can presumably become an important tool at a later stage. Hydraulic field tests investigating the effect of guiding walls are difficult for practical reasons. The most feasible alternative at an initial 
stage is to make a physical scale model in the laboratory in such a way that the results can be scaled up to protype conditions. Prior to the physical scale model, field tests of the fish behavior and the bathymetry in the confluence area, were conducted to be used as boundary conditions for the design of the attraction flow.

\section{Method}

\subsection{Hydropower Plant Case Study}

River Vindelälven in the northern part of Sweden is the largest tributary in Sweden with a length of $453 \mathrm{~km}$ and an annual mean flow rate of $190 \mathrm{~m}^{3} / \mathrm{s}$, Edlund [18]. It is proclaimed a national river of Sweden implying that it is unregulated and protected by Swedish constitutional laws. The river and its surroundings are a UNESCO biosphere reserve and an important breeding ground for Atlantic salmon and anadromous brown trout.

Between river Vindelälven and the Baltic sea, the Stornorrfors hydropower plant constitutes a potential barrier for the migrating fish. It is one of the largest hydropower plants in Sweden and the one which normally produces most electricity and is therefore of great strategic importance. The fish passage past the barrier is the $8 \mathrm{~km}$ long old river channel with a fish ladder at its upstream end, see Figure 1. The fish ladder is $300 \mathrm{~m}$ long and of vertical slot type in 76 steps and was built in 2010. It is the longest fish ladder in Sweden and one of the most modern in Europe, allowing for both upstream and downstream migration. The volume flow rate in the fish ladder is $1 \mathrm{~m}^{3} / \mathrm{s}$ and the local attraction flow at the entrance to the fish ladder has a velocity of $2 \mathrm{~m} / \mathrm{s}$, which has been proven to be attractive for the fish.

For upstream migration through the fish ladder, the confluence area between the hydropower plant tailrace channel and the old river channel, see Figure 1, has been shown to be a major obstacle. The attraction from the tailrace channel is most of the time too large in comparison, having an inhibiting effect on the fish ability to locate the attraction flow from the old river channel as intended. This has a negative impact on first the residence time in the confluence area and eventually the passage efficiency. Based on extensive field studies and experience of flow and fish behavior on the site of the present case study, e.g. Lundqvist et al. [30] and Andersson et al. [1], together with recommendations in fish pass handbooks (see above), the situation in the confluence area can possibly be improved by changing and improving the attraction flow from the old river channel. The alternatives are to either attract the fish before they reach the turbine tunnel outlet or after they return from the turbine tunnel outlet, which they do several times per day, when they realize that they cannot get further.

During the migration season, i.e. end of May to end of September, see Thorstad [38], the average temperature in the confluence area is around $18^{\circ} \mathrm{C}$, and the size range of the adult Atlantic salmon is between 0.4-1.4 m, and Brown trout is in the range 0.4-1.1 m, Forssén [19]. The average migration success from the confluence area to the dam upstream of the fish ladder has been about $25-40 \%$ since the mid 90-ties, Lundqvist [30]. However, during the best year so far, 2013, it was as high as $60 \%$ when 15000 fish passed. The success rate depends on how high the flow rate has been through the hydropower plant and out through the tunnel in relation to the flow rate in the old river channel. The success rate should generally be higher now since a difficult passage in Baggböle in the old river channel was remedied. Unfortunately, due to the reduced health of the Salmon since 2014, reason so far unknown, there is no fair number to compare with. For a description of the issue with the attraction flow in the confluence area, see also Lindberg et al. [29].
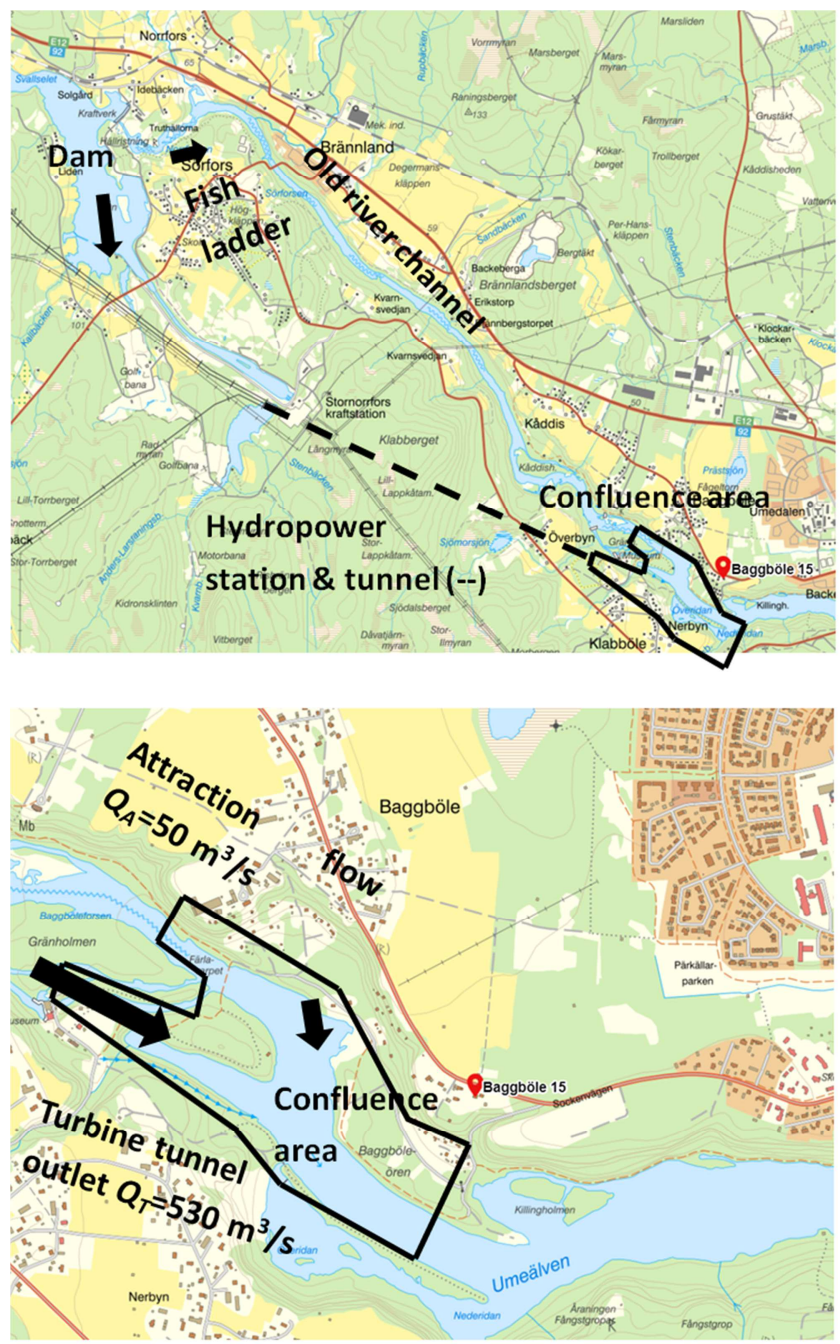

Figure 1. Maps over the case study area, Lantmäteriet [24]. The area within the black lines correspond to the physically modelled area in the scaled experiment, see Figure 2. $Q_{A}$ corresponds to the relatively small attraction flow from the old river channel and $Q_{T}$ corresponds to the substantially larger flow from the turbines in the hydropower plant tailrace.

Angele [3], designed a modification to the entrance of the fish ladder in a 1:50 scale physical model with the purpose of acting as a protection for the attraction flow out from the fish ladder in cases where one needs to spill up to $400 \mathrm{~m}^{3} / \mathrm{s}$ in the B-spillway, which normally only has a flowrate of $21-50 \mathrm{~m}^{3} / \mathrm{s}$ forming the attraction flow for the confluence area. A curved wedge-shaped wall on the right side (in the flow direction) of the B-spillway, 
which changes the direction of the spill flow from the B-gate away from the fish ladder entrance, proved to be an effective measure. In the present study we take the next step and focus on improving the attraction flow in the confluence area.

Hemström [21] carried out CFD simulations for the first time investigating the potential of using a single guiding wall along the northern shore to create a better attraction flow in the confluence area. However, by this design the attraction flow jet meets the flow from the tailrace at an almost perpendicular angle. A smaller angle between the two flows is desirable, see Pavlov [31], Armstrong [5] and DWA [16].

Finally, the old river channel can also be considered as a biotope per se, not only a fish passage for migrating fish. Widén et al. [40] reported a total of 17 species in the Ume-river. Of these only a few species live and migrate in the old river channel, e.g. Atlantic salmon, brown trout, grayling (Thymallus thymallus), burbot (Lota lota), whitefish (Coregonus sp.), minnow (Phoxinus phoxinus) and bullhead (Gottus gobio). To assess the influence of the flow rate in the old river channel on the preferences for the fish in a biotope perspective, a biological and hydraulic field investigation was made, Angele [2]. A 2D transient, hydraulic model using Hydraulic Engineering Center River Analysis System (HEC-RAS) was also conducted, see also Burman [10], in which different flow scenarios were tested. The conclusion was that the fish preferences in terms of local water velocity and water depth were optimized for a flow rate of $10 \mathrm{~m}^{3} / \mathrm{s}$ in the old river channel. In the present study, however, the focus is on the attraction of the upstream migrating fish in the confluence area at the end of the old river channel.

\subsection{Flow Conditions}

Table 1. Mean values of the flow rates in the hydropower plant tailrace, $Q_{T}$, the attraction flow in the old river channel $Q_{A}$, and the water level above sea level in the confluence area, $H_{C}$ (reference case marked with bold letters).

\begin{tabular}{lll}
\hline $\boldsymbol{Q}_{\boldsymbol{T}}\left(\mathrm{m}^{\mathbf{3}} / \mathbf{s}\right)$ & $\boldsymbol{Q}_{\boldsymbol{A}}\left(\mathrm{m}^{\mathbf{3}} / \mathbf{s}\right)$ & $\boldsymbol{H}_{\boldsymbol{C}}(\mathbf{m})$ in RH00 \\
\hline 530 & 21 & $0.0 \pm 1$ \\
900 & 21 & $0.8 \pm 1$ \\
530 & 50 & $0.0 \pm 1$ \\
900 & 50 & $0.8 \pm 1$ \\
0 & 200 & $-0.7 \pm 1$ \\
0 & 500 & $-0.1 \pm 1$ \\
0 & 1000 & $0.8 \pm 1$ \\
0 & 2000 & $3.0 \pm 1$ \\
0 & 3000 & $4.6 \pm 1$ \\
\hline
\end{tabular}

Table 1 shows the flow conditions in the confluence area based on an investigation of the measured data for the hydropower plant between 2012 and 2017 during the summer months (end of May to end of September) when the salmon migrates. The average flow rate in the tailrace during May and September, $Q_{\mathrm{T}}$, was $530 \mathrm{~m}^{3} / \mathrm{s}$ but it could reach as high as $900 \mathrm{~m}^{3} / \mathrm{s}$, i.e. the capacity of the hydropower station. The water level above sea level in the confluence area, $H_{\mathrm{C}}$, increases with the flow rate, as can be seen in Figure 2, and for the average flow rate $530 \mathrm{~m}^{3} / \mathrm{s}$ the nominal water level was $0.0 \mathrm{~m}$ given in the RH00-system.

Higher flow rates in the old river channel can also occur due to floods. In worst case a simultaneous outage of the hydropower station, requiring the dam spillways to be opened and the water to be spilled through the old river channel, can occur.

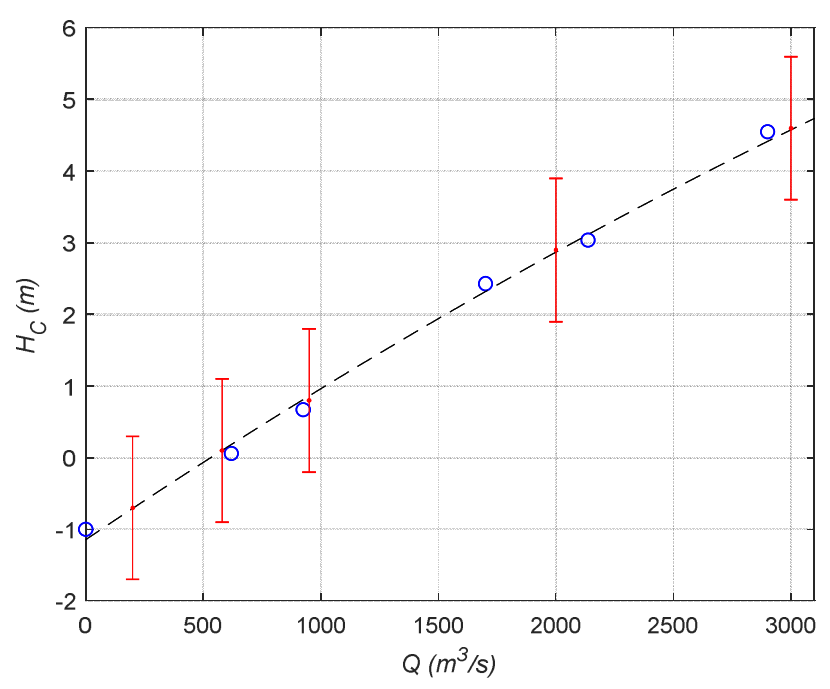

Figure 2. Measured (o) and interpolated (---) water levels in the confluence area, $H_{C}$, as a function of the total flow rate through the confluence area. The red vertical bars correspond to $H_{C} \pm 1 \mathrm{~m}$ for the investigated flow rates, see Table 1 .

The four spillways in the dam have a total capacity of 4500 $\mathrm{m}^{3} / \mathrm{s}$ but this has never been used. The highest flow rate in recent years was about $2500 \mathrm{~m}^{3} / \mathrm{s}$ during the 80 -ties. A total flow rate (i.e. the sum of the flows through the hydropower plant and the spill flow rate in the old river channel) up to about $1500 \mathrm{~m}^{3} / \mathrm{s}$ is not common but do occur a few times over a period of 10 years. Flow rates up to $3000 \mathrm{~m}^{3} / \mathrm{s}$ in the old river channel were tested here, see Table 1 and Figure 2 to have a margin.

The attraction flow consists of $1 \mathrm{~m}^{3} / \mathrm{s}$ through the fish ladder, $20 \mathrm{~m}^{3} / \mathrm{s}$ through a parallel small scale turbine with a common exit with the fish ladder and the rest $\left(29 \mathrm{~m}^{3} / \mathrm{s}\right.$ in the case of a total attraction flow of $50 \mathrm{~m}^{3} / \mathrm{s}$ at the confluence area) through the B-spillway gate.

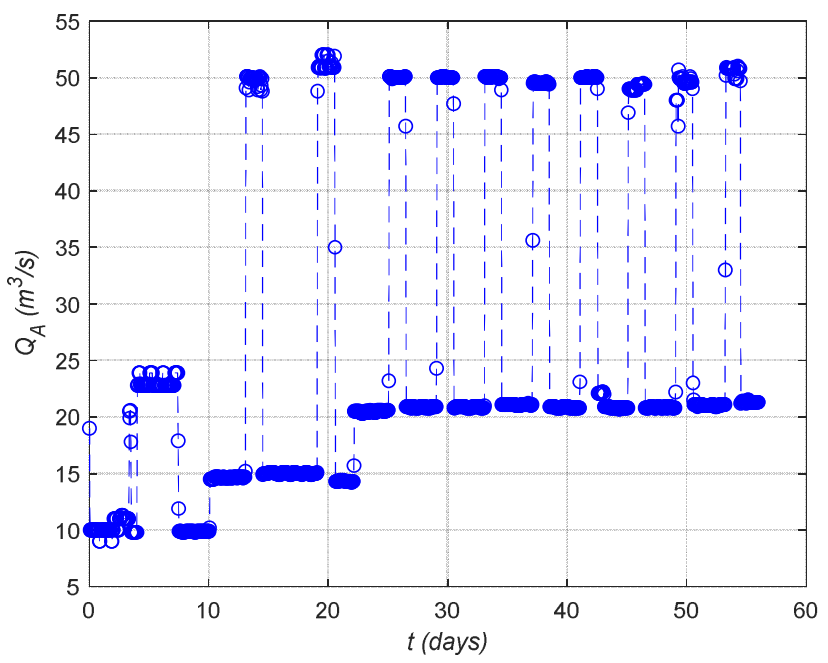

Figure 3. Measured attraction flow rate in the old river channel during June and July 2018. 


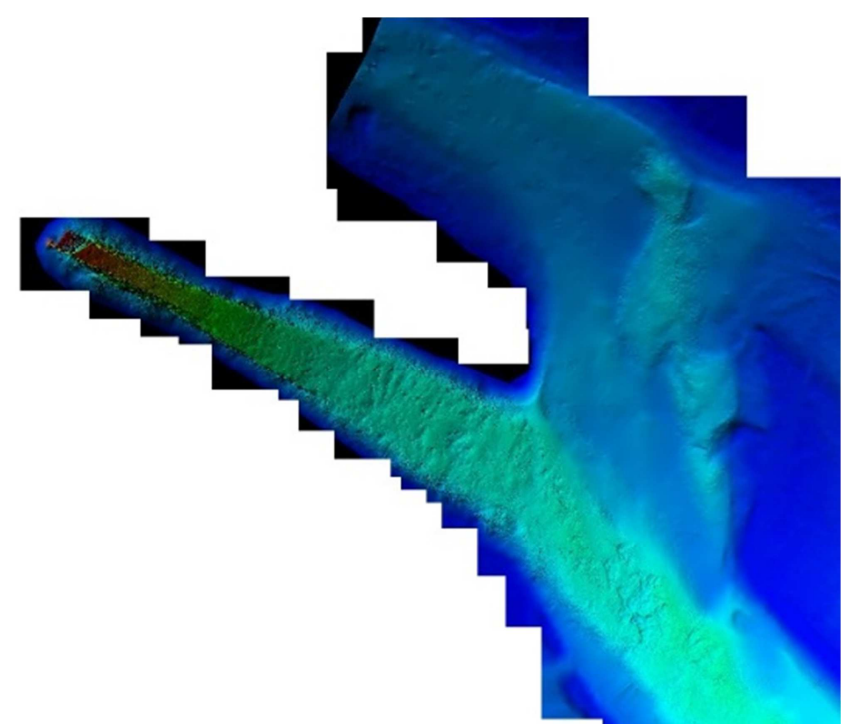

Figure 4. Bathymetry in the confluence area based on sonar measurements.

Measurements of the attraction flow which was spilled through the fish ladder and the B-spillway in the dam during the summer 2018 are shown in Figure 3. One can see how the flow rate was intentionally varied daily between $21 \mathrm{~m}^{3} / \mathrm{s}$ and $50 \mathrm{~m}^{3} / \mathrm{s}$. The many flow peaks, so called freshets, have been shown to have a positive impact on the attraction of salmon in Stornorrfors and several other rivers, Calles [12] and Lundqvist et al. [30].

Natural variations in the sea water level in the Baltic sea are usually about $\pm 0.5 \mathrm{~m}$, however they can in extreme cases be as high as $\pm 1 \mathrm{~m}$. All cases in the test matrix were tested for the nominal water level $H_{C} \pm 1 \mathrm{~m}$, see Table 1 and Figure 2 .

\subsection{Sonar Measurements Bathymetry Data of the River Bottom}

In the summer of 2018, a detailed field survey of the local river bottom bathymetry was carried out in the confluence area. A multi-beam sonar (Reson $8125^{\circledR}$ ) was used in the measurements of the deeper areas in the main channel. The spatial resolution was $0.3 \mathrm{~m}$ or less. A single beam sonar (Deepvision Depth Logger ${ }^{\circledR}$ ) was used in the shallower parts. The uncertainty in the depth position for both was below $0.1 \mathrm{~m}$ The transversal spatial resolution in the measurements in a transect was about 0.2-0.3 m, however the distance between successive transects were up to $30 \mathrm{~m}$ at some positions in the old river channel requiring interpolation of the data. Some points in the shallow part in the old river channel were also measured using a manual GPS-pole with network RTK (Leica ${ }^{\circledR}$ GS14) when the depth was too shallow for the boat. The acquired data were used to create a digital 3D-model of the bathymetry of the confluence area, shown in Figure 4, where the deepest areas colored dark red at the tunnel exit in the tailrace channel corresponds to $-12 \mathrm{~m}$, green in the confluence area corresponds to $-9 \mathrm{~m}$, turquoise/light blue in the old river channel corresponds to $-2 \mathrm{~m}$ and dark blue on the shores (from the national database with a similar spatial resolution and accuracy) corresponds to $+6 \mathrm{~m}$.

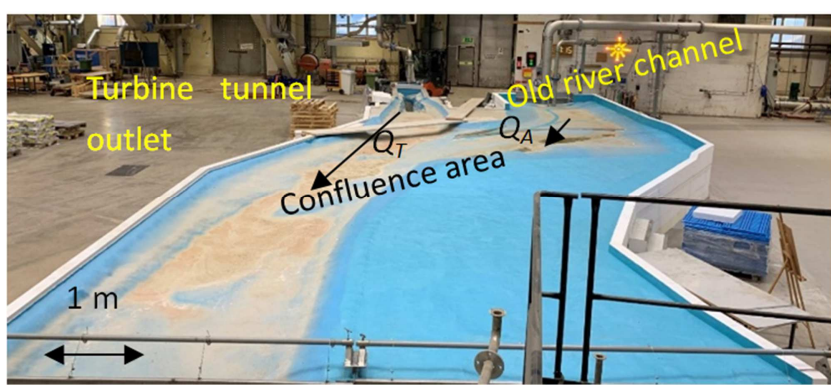

Figure 5. The physical scale model in the laboratory.

\subsection{Physical Scale Model}

The hydraulic design of the attraction flow channel was carried out experimentally in a 1:50 physical scale model of the confluence area in the Vattenfall Älvkarleby laboratory, see Figure 5.

The physical model was 3D-milled in Styrofoam (Frigolit ${ }^{\circledR}$ ) based on the digital 3D-model of the river bottom bathymetry in Figure 4 and three thin layers of water-resistant paint was applied on the terrain for the physical scale model to be sealed. The physical scale model consisted of three layers of 43 blocks each, where the block size was $2.4 \mathrm{~m}$ x $1.2 \mathrm{~m}$ x 0.3 $\mathrm{m}$. The resolution in the milling was generally $0.1 \mathrm{~mm}$ but the largest discrepancies with the largest milling tool (which had a diameter of $16 \mathrm{~mm}$ ) was $10 \mathrm{~mm}$ locally.

The whole physical model was $20 \mathrm{~m}$ long and $10 \mathrm{~m}$ wide corresponding to about $1000 \mathrm{~m} \times 500 \mathrm{~m}$ in prototype.

The highest points in the model corresponds to $6 \mathrm{~m}$ above sea level in prototype.

As a quality check, a control scanning in reflector less mode using a Leica ${ }^{\circledR}$ MS50 total station was carried out and it became evident that the largest discrepancies arose from the fact that the building blocks were not in their exact positions. In a few cases the discrepancies were larger than $10 \mathrm{~mm}$ in the physical scale model. However, the focus here was primarily on the bulk velocities and overall depths in the confluence area and small local differences between the prototype and the model should not have a large impact on the global flow picture and the main conclusions. In general, the overall discrepancies are much smaller.

The infrastructure around the physical scale model and the instrumentation is shown schematically in the flowchart in Figure 6. The water was supplied to the model through four separate pipelines from a high-level water reservoir, which was used to create stable inflow conditions. The pipe, which feeds the turbine tunnel outlet of the hydropower tailrace channel, was a DN150 pipe and it provided up to $80 \mathrm{l} / \mathrm{s}$. For lower flow rates to the attraction flow in the old river channel, the water was separately supplied by a DN25-pipe line (with a capacity of $2.3 \mathrm{l} / \mathrm{s}$ ). For intermediate flow rate cases, a DN80-pipe line with a capacity of $431 / \mathrm{s}$ was used and for high flow rate cases a DN300-pipe. The DN25-pipe line also had a T-junction where hot water from a separate reservoir was supplied for flow visualizations using an infrared camera, see section 2.5.5. 


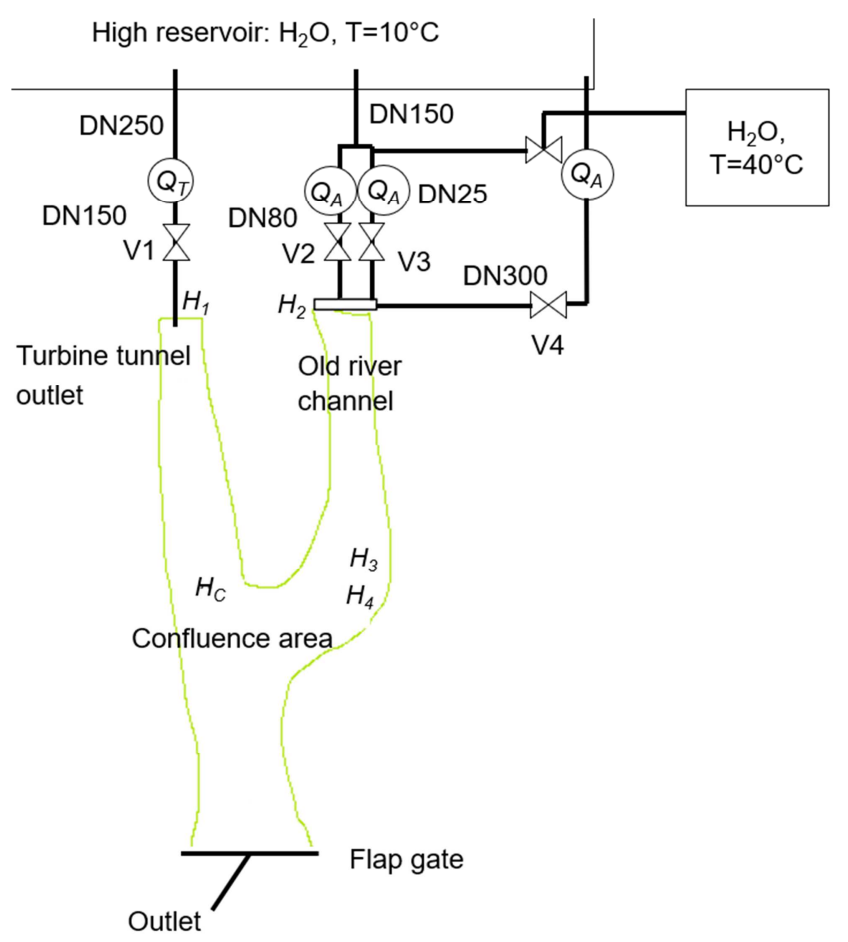

Figure 6. Schematic flow chart description of the infrastructure around the physical scale model as well as the instrumentation. $\mathrm{H}_{C}, \mathrm{H}_{1}, \mathrm{H}_{2}, \mathrm{H}_{3}$ and $\mathrm{H}_{4}$ indicate the positions of the water level measurements and $Q_{T}$ and $Q_{A}$ indicate the positions of the flowmeters.

The flow rates were regulated using control valves on the inlet pipes (V1, V2, V3 and V4) and the water level in the model was regulated by a flap gate before the outlet of the model. The inlets were equipped with large (in relation to the inlet pies) boxes with perforated plates so that the inflows should be evenly distributed over the inlets.

\subsection{Instrumentation of the Physical Scale Model}

\subsubsection{Flow Rate Measurements}

The flow rates at the inlets were measured using externally calibrated (by a certified company, Statens provningsanstalt) electromagnetic flowmeters from Krohne ${ }^{\circledR}$. The flowmeters were shown to be linear with an uncertainty of about $\pm 0.5 \%$ according to the calibration protocols. At one inlet two flow meters were installed in series in order to increase the reliability in the measurement. The installation of the flow meters was done in accordance with the recommendations by the manufacturer of having a straight pipe with a length of at least five pipe diameters $(D)$ upstream of the sensors and at least two pipe diameters downstream of the sensors. Here these distances were doubled to $10 \mathrm{D}$ and $5 \mathrm{D}$ respectively. The diameters of the flowmeters were chosen so that the velocity was high enough $(1-10 \mathrm{~m} / \mathrm{s})$ for the uncertainty to be $0.5 \%$ since the uncertainty increases once the velocity becomes sufficiently below $1 \mathrm{~m} / \mathrm{s}$.

\subsubsection{Water Level Measurements}

The water levels in the physical scale model (at the two inlets $H_{1}$ and $H_{2}$, in the confluence area, $H_{C}$, and on the upstream and downstream sides of the outer guiding wall, $H_{3}$ and $H_{4}$ ) were measured using in-house built and in-house calibrated electro-restrictive level meters with an uncertainty of $\pm 0.1 \mathrm{~mm}$ according to the calibrations. The measurement positions are indicated in Figure 6. $H_{C}$ was close to the position where the water level was measured in the prototype. Rulers were also used for rough measurements and to visualize the water levels. The water level in the physical scale model tests was varied between $-34 \mathrm{~mm}$ and $112 \mathrm{~mm}$, corresponding to $-1.7 \mathrm{~m}$ and $5.6 \mathrm{~m}$ above sea level in the RH00 system in the prototype, see the test matrix in Table 1 and Figure 2.

\subsubsection{Measurement System for Data Acquisition}

All signals from the flow meters and water level sensors were sampled during one minute at a frequency of $f=1 \mathrm{kHz}$ and the data was collected using a National Instruments ${ }^{\circledR}$ DAQ data acquisition system with the software LabView ${ }^{\circledR}$.

All computed mean values of the flow rates and the water levels were shown to be stable and repeatable within the uncertainties of the respective measurement methods, a prerequisite for all measurements.

\subsubsection{Velocity Measurements}

A P-TAD rotameter from Höntzsch Instruments ${ }^{\circledR}$ with a diameter of $10 \mathrm{~mm}$ was used for local point measurements of the mean velocity in the confluence area. The sampling time was $10 \mathrm{~s}$ at a time with several repetitions. Special attention was payed to the attraction flow between the guiding walls, specifically at the outlet of the proposed attraction flow channel. The uncertainty was about $0.05 \mathrm{~m} / \mathrm{s}$ between $1-10$ $\mathrm{m} / \mathrm{s}$.

The movement of the surface water was also measured using Particle Tracking Velocimetry (PTV) with a $1536 \mathrm{x}$ 2048-pixel digital camera filming at $30 \mathrm{~Hz}$. White and black plastic particles from Sinfotek ${ }^{\circledR}$, designed for the purpose, with a diameter of $11 \mathrm{~mm}$ were used as seeding. A MATLAB $^{\circledR}$ PTV-code, Sveen [37], was used for calculating the velocities from the images of particles and for the post-processing. The code was also internally verified for its purpose by comparisons to measurements using the rotameter in a well-defined open square channel flow.

\subsubsection{Mixing Measurements Using Infrared Camera}

The movement of the two flows from the old river channel and the turbine tunnel outlet and how they mix in the confluence area was visualized and quantified by using warm water as a passive tracer and filming it at $30 \mathrm{~Hz}$ with an infrared camera from FLIR $\AA$. The resolution of the infrared camera was $0.1^{\circ} \mathrm{C}$ and the uncertainty was $1^{\circ} \mathrm{C}$. This was accomplished by supplying hot water, $40^{\circ} \mathrm{C}$, from a separate tank and mix that with the cold water from the high-level reservoir $\left(10^{\circ} \mathrm{C}\right)$ prior to the flow meter and the inlet to the old river channel part of the model, see Figure 6 . This gave a temperature of the water in the old river channel of about $20^{\circ} \mathrm{C}$. The temperature of the water in the turbine tunnel outlet from the high-level reservoir was always about $10^{\circ} \mathrm{C}$. The temperature difference of $10^{\circ} \mathrm{C}$ was small enough to not induce any buoyancy effects, i.e. the structure and character 
of the flow was identical to the one with fully cold conditions.

\subsection{Tagging and Tracking Fish in the Confluence Area}

\subsubsection{Acoustic Telemetry for 2D-positioning}

To investigate the migration behavior of salmon in the confluence area, acoustic telemetry was used. Acoustic telemetry is the leading tracking technology for fine-scale positioning of fish in lakes and rivers, Donaldson et al. [15]. It works by attaching a small transmitter to the fish which emits an ID-coded ultrasound signal that can be detected, decoded and time-stamped by acoustic receivers (hydrophones) deployed in the water, Pincock [34]. By applying multiple receivers in an array, tagged fish within the array can be positioned with high spatial resolution $(<1 \mathrm{~m})$ and temporal resolution $(f=1 \mathrm{~Hz})$ using positional algorithms. The positional methods used in the present study are described below.

In June and July 2017 and 2018, 225 migrating salmon were caught in the river mouth of river Ume using large trap-nets $(n=150, T L=0.89 \pm 0.09 \mathrm{~m}$ and $\mathrm{n}=75, \mathrm{TL}=0.74 \pm 0.15$ $\mathrm{m})$ and tagged with acoustic transmitters. The transmitters (either a VEMCO V9-2H $170 \mathrm{kHz}, 9 \mathrm{~mm}$ x $25 \mathrm{~mm}, 3.7 \mathrm{~g}$, signal-delay $=0.7 \pm 0.1 \mathrm{~s}$, or a VEMCO V16-4 $69 \mathrm{kHz}, 16 \times 65$ $\mathrm{mm}, 24 \mathrm{~g}$, signal delay $=40 \pm 15 \mathrm{~s}$ ) were inserted into the stomach of the salmon via the gastric tract, Liedtke [27], a procedure that take less than one minute. Here we excluded data from the long signal-delay transmitters since the salmon might move long distances between the signals, which makes it more uncertain which parts of the confluence area the salmon visited.

Acoustic receivers were deployed in the river to track the salmon from the river mouth up to the confluence area. An array of 16 Vemco HR2 receivers and 15 Vemco VR2AR in 2017, and 17 Vemco HR2 receivers and 15 Vemco VR2AR in 2018, were installed in the confluence area to derive high-resolution behavioral data of tagged salmon from June to October. In 2017, salmon were positioned using a commercial positioning service (Vemco Positioning System, VPS). VPS derived positions based on hyperbolic principles, using the time difference between receivers of the arrival (TDoA) of each unique transmission. In 2018, the positions were calculated using the time of flight (ToF) approach based on the method described by Baktoft et al. [6]. Wolfram Research Mathematica, Version 12.0 [41], was used for the calculations, analyses of the results, and for presenting the results on the maps. Note that only $2 \mathrm{D}$ in-plane positions of the fish are acquired with this method and no information about the depth position is received.

\subsubsection{Echo Sounding Study for Depth Positioning of the Fish}

In order to have information also about the depth distribution of the migrating salmon in the confluence area results from an earlier study where an echo sounder was used were included. A SIMRAD EK60 with an ES120-7C split beam transducer ( $7^{\circ}$ viewing angle) was positioned at the north side of the tailrace (6350'3.6"N 20 $\left.0^{\circ} 7^{\prime} 27.9^{\prime \prime} \mathrm{E}\right)$, facing the beam perpendicular to the flow. The transducer was mounted just under the surface pointing downwards $3.5^{\circ}$ such that the beam covered from the surface and downwards. The echo sounding measurement was performed during 19 August 2004. Sonar 5-pro, Balk [7], was used for post-processing the echogram files following Lindberg et al. [29]. A minimum target strength of $-31 \mathrm{~dB}$ was used, corresponding to a salmon length of about $40 \mathrm{~cm}$, Lilja et al. [28]. The fish counts at each depth interval were converted to relative frequencies based on the cone volume for each interval.

\subsection{Erosion Protection Design Method}

Events with high flow rates are rare but need to be considered when designing the guiding wall solution in the context of solid mechanical dimensioning of the construction as well as the design of erosion protection. To dimension the size of the erosion protection, $\beta_{50}$, the following formula was used, Vägverket [35]:

$$
\beta_{50}=0.04 \cdot u_{\mathrm{dim}}^{2.44}
$$

where the velocity $u_{\text {dim. }}=1.5 \cdot u$, where $u$ was the local mean velocity. This is in essentially a simplification of Shield's classical stability concept for sediment transport of coarse material, see e.g. Carling [13].

\subsection{Applicability of the Model Test Results at Prototype Conditions}

A prerequisite for the validity of the present study is that all the results can be properly scaled up and are applicable at prototype conditions.

The physical model was scaled according to the scaling laws of Froude:

$$
F r=\frac{u}{(g H)^{1 / 2}}
$$

where $g=9.82 \mathrm{~m} / \mathrm{s}^{2}, H$ is the local water depth and $u$ is the local velocity. This is the primary scaling method for flows with a free water surface such as here, where the flow is primarily governed by a balance between the inertial and gravitational forces. $F r$ in the prototype and the model was kept constant so that the character of the flow at model scale becomes representative for the conditions in the prototype. This scaling leads to a time scale which becomes $\lambda^{0.5}=7.1$ times smaller than in the prototype when the model scale, $\lambda=50$. The flow rate, which is proportional to both the velocity and the length scale, becomes $\lambda^{2.5}=17.7 \cdot 10^{3}$ times smaller than in the prototype, i.e. $530 \mathrm{~m}^{3} / \mathrm{s}$ corresponds to $30.0 \mathrm{l} / \mathrm{s}$ in the physical scale model. All measured values of local velocities and water depths must then be up scaled to prototype conditions. The larger the scaled model is, the more similar the results will be to the prototype. However, it is difficult, i.e. time and space consuming and thereby expensive, to make the physical scale model large.

However, the model scale cannot be made too small because then the uncertainties in the measured quantities will become 
too large and even more important the effects of viscosity will become too large as is reflected by the Reynolds:

$$
R e \approx \frac{4 H u}{v}
$$

which is the ratio between the inertial forces and the viscous forces, where $v$ is the water viscosity, $v=10^{-6}$ at $T=20^{\circ} \mathrm{C}$. $R e$ is used to characterize the nature of the flow, i.e. if it is laminar or turbulent. For a channel type flow with a free surface, such as here, the flow is laminar for $\operatorname{Re}<5 \cdot 10^{3}$ and turbulent for $R e>5 \cdot 10^{3}$. In the prototype $R e=5.0 \cdot 106$ in the tailrace channel and $R e=1.7 \cdot 10^{5}$ in the old river channel, i.e. fully turbulent. With the present model scale $R e$ is sufficiently large in the jet in the case with the attraction flow channel using guiding walls, $R e=1.3 \cdot 10^{4}$, and in the tailrace channel $R e=1.5 \cdot 10^{4}$, however, for the reference case without the guiding walls $\mathrm{Re}$ becomes too low locally in the old river channel, $R e=5 \cdot 10^{2}$, where the velocity is low, $u=0.1 \mathrm{~m} / \mathrm{s}$ and the local water depth shallow. The turbulent nature of the mixing between the attraction flow and the flow from the tailrace channel downstream of the confluence area becomes obvious as indicated by the small scale vortical structures even for this case, Figure 7. The focus here is on the cases with the guiding walls and the attraction flow jet and the conclusion is that the results from the scaled physical model tests of the present case study safely can be scaled up to prototype conditions when it comes to the aspects of capturing the turbulent nature of the attraction flow correctly, even though the span of turbulent scales naturally becomes lower. Furthermore, $R e$ is of secondary importance after $F r$.

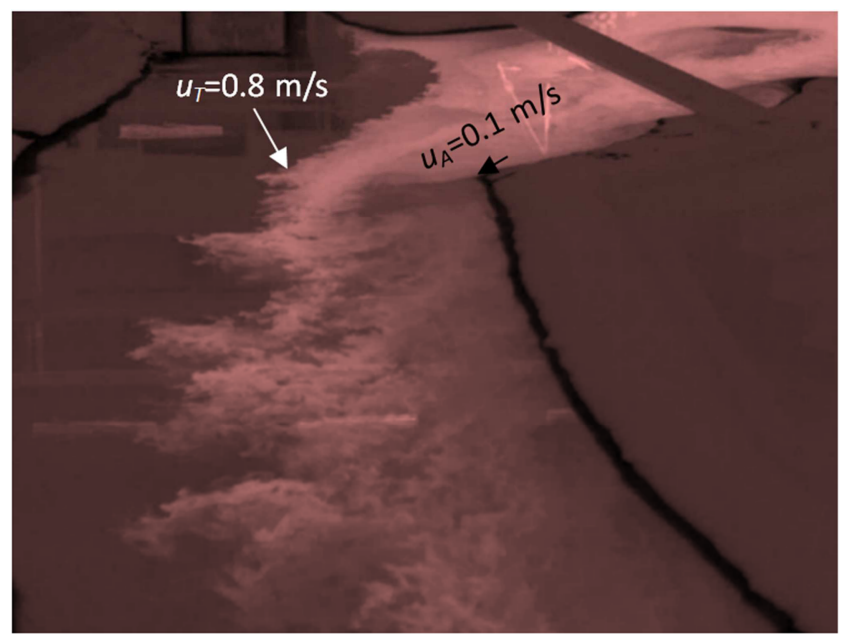

Figure 7. Flow visualization using the infrared FLIR-camera for the present case without guiding walls for $Q_{T}=530 \mathrm{~m}^{3} / \mathrm{s}, Q_{A}=50 \mathrm{~m}^{3} / \mathrm{s}$ and $H_{C}=0.0 \mathrm{~m}$. The turbulent mixing between the attraction flow (bright color) and the turbine flow (dark color) is evident.

The third, least relevant, dimensionless number is the Weber number:

$$
W e \approx \frac{\rho 4 H u^{2}}{\sigma}
$$

expressing the ratio between the inertial forces and the $\mathrm{f}$ orces associated with the surface tension of water, $\sigma=7.2$
$86 \cdot 10^{-2}$ at $T=20^{\circ} \mathrm{C}$. At prototype conditions in the attract ion flow channel, $W e=6.9 \cdot 10^{5}$ and in the physical scale model here $W e=2.8 \cdot 10^{2}$ so surface tension effects becom e disproportionate in a physical Froude-scaled model. Ho wever, $W e>10-100$, which was set as the limit, see Peak all [32], so the character of the flow is still not govern ed by surface tension at the model scale $\lambda=50$.

The conclusion is that the results from the scaled physical model tests at $\lambda=50$ of the present case study can be safely scaled up to prototype conditions.

All hydraulic conditions i.e. flow rate, water level and velocity were scaled up to prototype conditions throughout the whole results section.

All hydraulic conditions i.e. flow rate, water level and velocity were scaled up to prototype conditions throughout the whole results section.

\section{Results}

\subsection{Reference Case: Attraction Flow at Present State}

The results for the reference case, where $Q_{T}=530 \mathrm{~m}^{3} / \mathrm{s}$, $Q_{A}=50 \mathrm{~m}^{3} / \mathrm{s}$ and $H_{C}=0.0 \mathrm{~m}$, corresponding to the present state without guiding walls is shown in Figure 7 in terms of a flow visualization using the infrared camera. The attraction flow has a temperature of about $T_{A}=20^{\circ} \mathrm{C}$ (bright color) and the turbine flow (dark color) a temperature of about $T_{T}=10^{\circ} \mathrm{C}$. Figure 7 shows how the attraction flow is concentrated to the left part of the old river channel, when seen in the flow direction, as it enters the confluence area.

The measured values of the mean velocity from the local velocity measurements using the rotameter were also included. For this case the flow rate from the turbine tunnel was about ten times higher than the flow rate of the attraction flow from the old river channel. The velocity of the attraction flow at the outlet of the old river channel became about $0.1 \mathrm{~m} / \mathrm{s}$ and the velocity in the tailrace became $0.8 \mathrm{~m} / \mathrm{s}$.

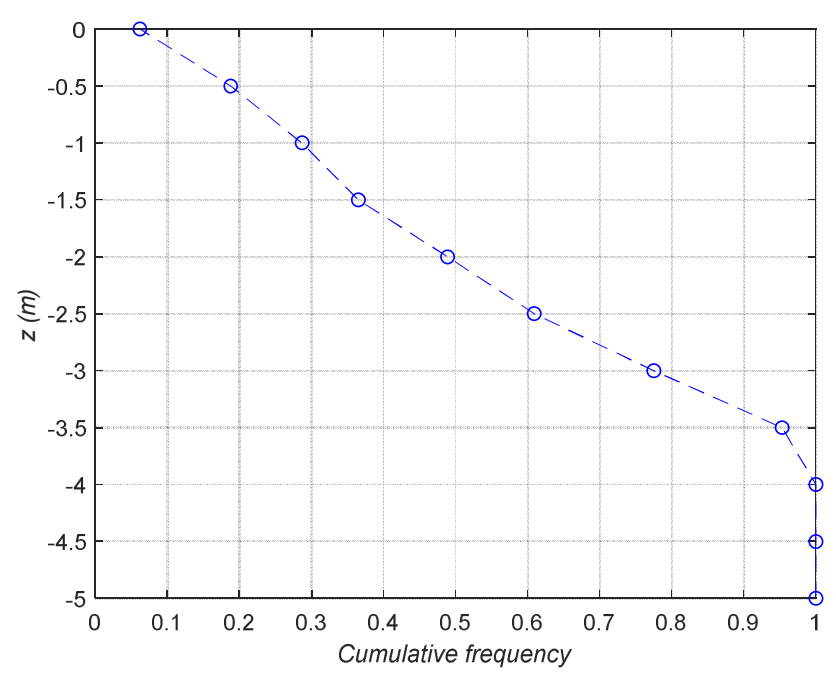

Figure 8. The depth distribution of the fish displayed as the cumulative frequency from 0 to 1 . 


\subsection{Fish Positioning and Attraction Flow Channel Configurations}

\subsubsection{Fish Positioning}

The field test with echo sounding recorded in total 353 fish tracks with target strengths corresponding to salmon with a size larger than $0.4 \mathrm{~m}$. The distribution of the fish in the depth direction, displayed as the cumulative frequency from 0 to 1 , was almost even from the surface and down to about $3.5 \mathrm{~m}$, see Figure 8 . No fish were recorded below $4 \mathrm{~m}$ where the local water depth increases rapidly to $9 \mathrm{~m}$ according to the topography in Figure 2.

The results from the field tests using acoustic telemetry for the positioning of the fish are displayed as traces of individual fish in Figure 9a and the density plot of all fish positions in Figure $9 \mathrm{~b}$. The salmon that did not find the old river channel spent between three and five days searching in the entire area, including the tailrace channel, before they gave up and returned to the sea, Lundqvist et al. [30]. Each salmon had more than one chance of finding the attraction flow.

\subsubsection{Attraction Flow Channel Configurations}

Based on the results from the fish positioning field tests, three configurations of attraction flow guiding walls were designed, see Figure 10. The principle of all configurations was guiding walls in the old river channel, which concentrated the attraction flow and generated a jet with high velocity penetrating into the main flow in the confluence area.

The first configuration was like the one by Hemström [21] with the benefit of using a single guiding wall along the northern shore. This however resulted in unwanted hydraulic jumps further up in the longer and more narrow attraction flow channel. Most important, the single wall was not able to keep the jet concentrated, see Figure 11b.
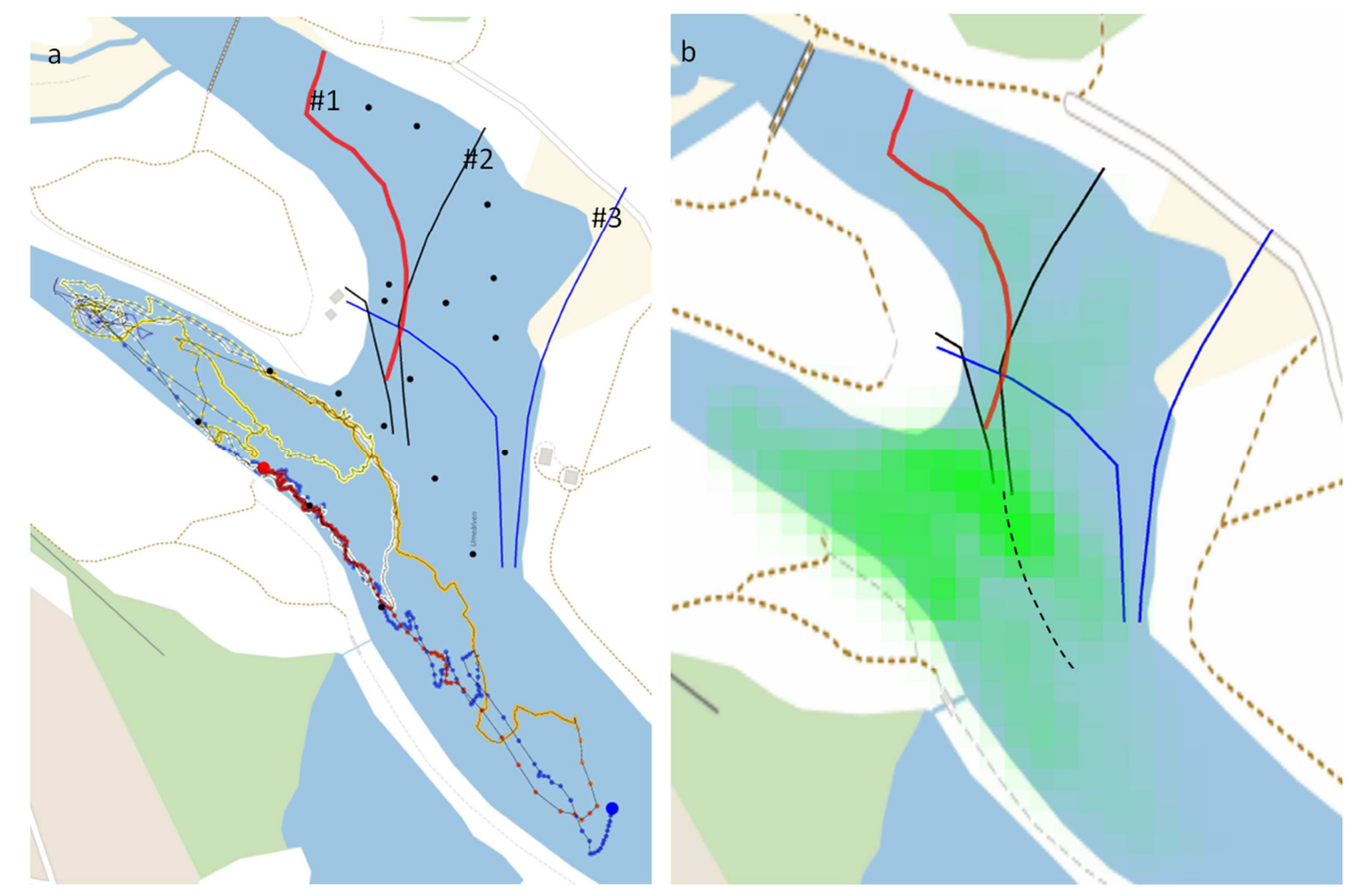

Figure 9. Traces of individual tagged fish and (b) density plot of all fish in-plane positions in the confluence area. Attraction flow channel guiding walls, configuration 1 (red thick line), 2 (black line) and 3 (blue line). (- -) Approximate attraction flow path. OOpenStreetMap contributors.

In order to keep the jet concentrated and also attract fish a little bit earlier in the confluence area, where the fish spent most of the time according to the results in Figure 9, the solution required two guiding walls, see configuration 2 in Figure 10. Using two walls one could also aim the jet in a more optimal angle with respect to the flow from the tailrace channel compared to configuration 1 . The third configuration was essentially identical to the second, only shifted towards the other shore and aiming at attracting the fish even earlier.

\subsection{Attraction Flow Improvement Using Guiding Walls}

The attraction flow from the old river channel was slowly entering the inlet part to the attraction flow channel in between the guiding walls. The decreasing distance between the guiding walls in the stream wise direction slowly accelerated the attraction flow successively through the contraction and finally emitted a concentrated jet at the outlet of the attraction flow channel.

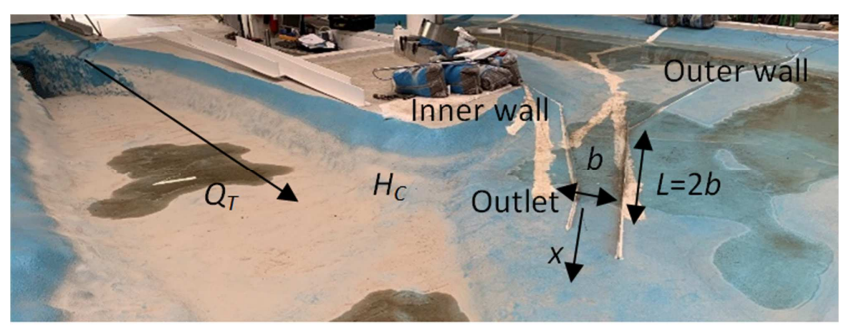

Figure 10. Guiding walls with configuration 2 in the old river channel. 

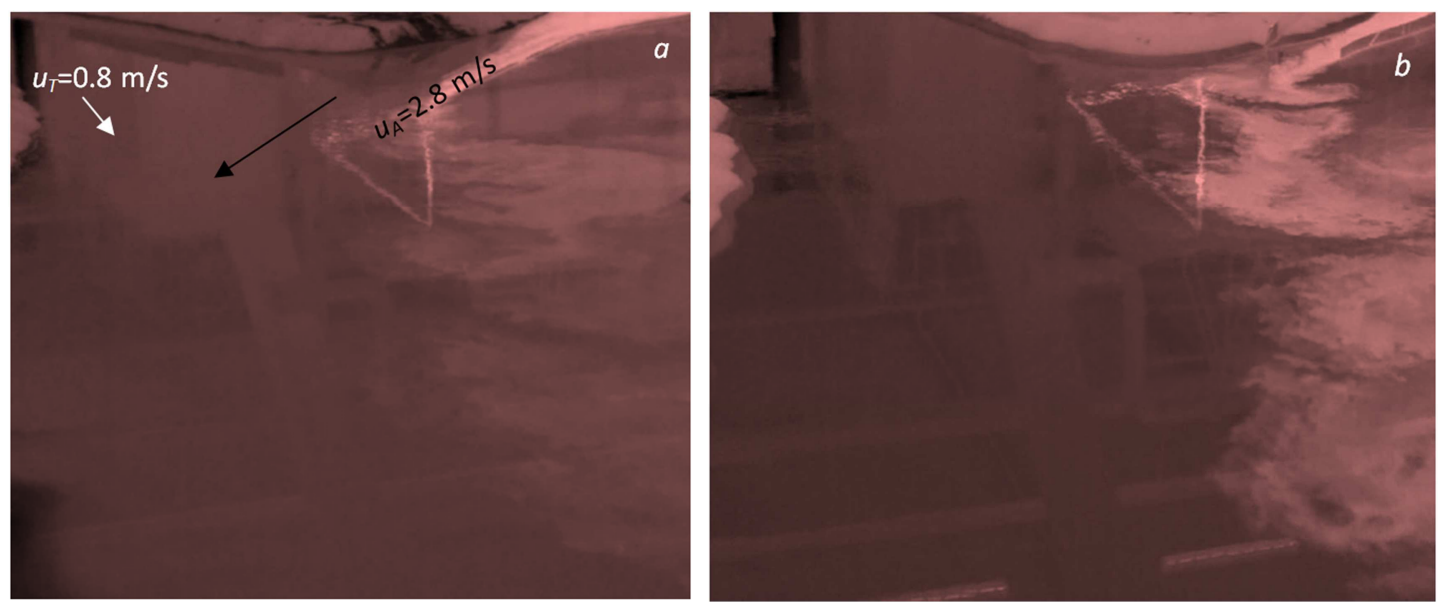

Figure 11. (a) Configuration 2 and (b) configuration 1, with $b=11 \mathrm{~m}$ for the case $Q_{T}=530 \mathrm{~m}^{3} / \mathrm{s}, Q_{A}=50 \mathrm{~m}^{3} / \mathrm{s}$ and $H_{C}=0.0$ m. Velocities measured with the rotameter and mixing in the confluence area visualized with the FLIR camera. Note: the bright triangle is a reflection from the pipe providing the hot water.

\subsubsection{Mixing Measurements}

The jet velocity was high, and the attraction flow reached out almost to the middle of the main river in the confluence area as is shown in Figure 11 in the flow visualization and mixing quantification using the infrared camera. Figure 11a shows how the attraction flow using configuration 2 formed a more concentrated jet, implying a higher velocity for a longer distance, which reached further out into the confluence area than with configuration 1, see Figure 11b.

Figure 12a shows an instantaneous image from local measurements with a higher spatial resolution. This illustrates the turbulent nature of the jet with characteristic large scale vortical structures, generated by the shear layer and velocity gradient between the two streams. A large vortical recirculation zone is generated on the leeward side of the attraction flow.
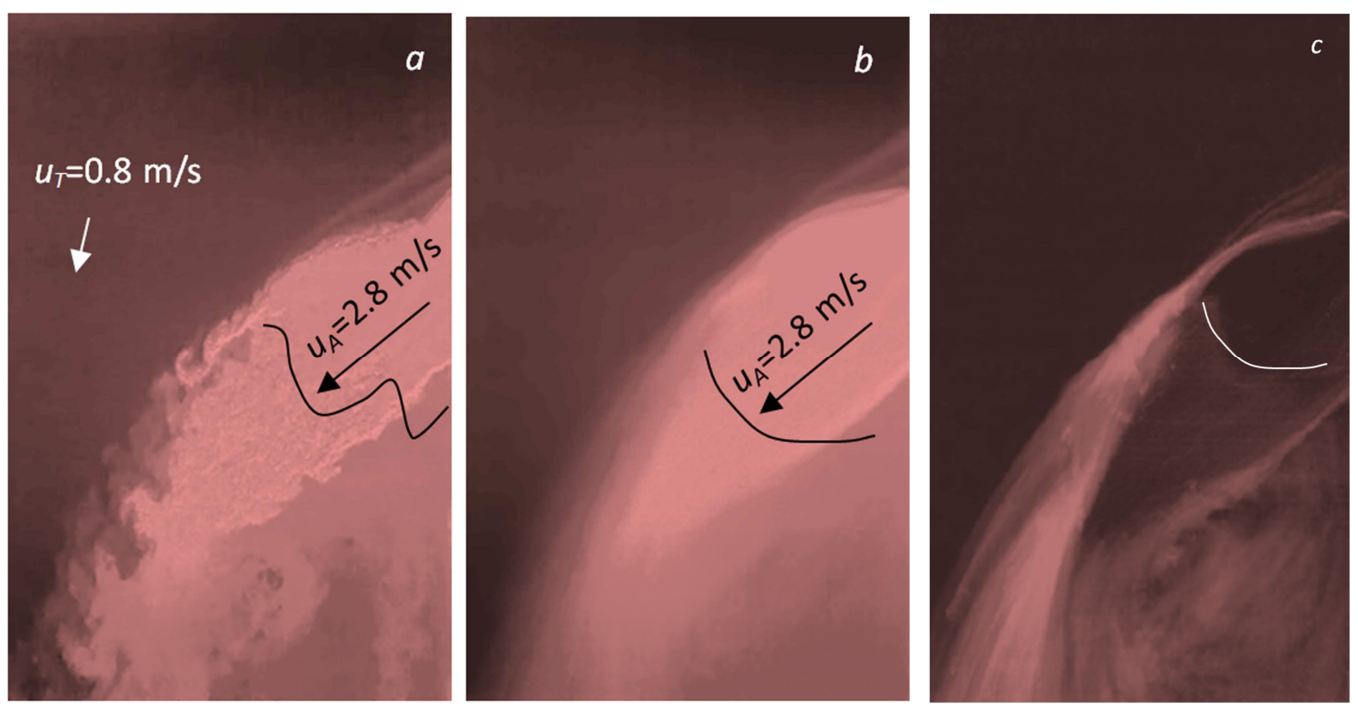

(a) Instantaneous image (b) $\mathrm{T}_{\text {mean }}$ and (c) $\mathrm{T}_{\text {rms. }}$. The lines illustrate the position of the hydraulic jump.

Figure 12. Visualization of the attraction flow channel for configuration 3 with $b=11 \mathrm{~m}$, for the case $Q_{T}=530 \mathrm{~m}^{3} / \mathrm{s}, Q_{A}=50 \mathrm{~m}^{3} / \mathrm{s}$ and $H_{C}=0.0 \mathrm{~m}$.

Figure $12 \mathrm{~b}$ and $\mathrm{c}$ shows the turbulence statistics, i.e. mean value, $T_{\text {mean }}$, and root mean square (rms) of the temperature, $T_{r m s}$, based on 228 measurements of the instantaneous temperature fields. The successive decrease of the mean temperature along the attraction flow indicates the mixing with the main flow from the tailrace channel. The maximum turbulence level $T_{r m s} / \Delta T$ is $20 \%$ in the shear layer in line with other mixing situations between hot and cold water e.g. Angele [4], Smith [35] and Braillard [9]. This essentially implies that the temperature was varying in almost the whole range between hot and cold.
The hydraulic jump, illustrated by the solid lines, induces turbulence and the recirculation zone on the leeward side of the jet also has a locally larger level of turbulence, see Figure 12c.

\subsubsection{Velocity Measurements}

Figure 13 and 14 shows instantaneous velocities measured with PTV at the outlet of the attraction flow channel. They were based on 160 and 200 particle images respectively. One can clearly see the hydraulic jump where the measured velocities abruptly become lower as the flow goes from super to sub critical when $H_{C}=0.0$. 
Figure 14 shows how the hydraulic jump disappears when the water level is increased to $H_{C}=1.0$. The small velocities in the opposite direction forming a large vortical recirculation zone on the leeward side of the attraction flow can also be seen in Figure 14.

\subsubsection{Channel Outlet Width Optimization}

The velocity at the outlet of the attraction flow channel, $u_{A}$, was measured and the width of the outlet of the attraction flow channel $(b)$ was varied and optimized to $b=11 \mathrm{~m}$ in the tests, see the results displayed in Figure 15.

The local water depth, which is $1.65 \mathrm{~m}$ at nominal conditions, was also measured and the local $\mathrm{Fr}_{A}$, (2), was calculated, see Figure 16.
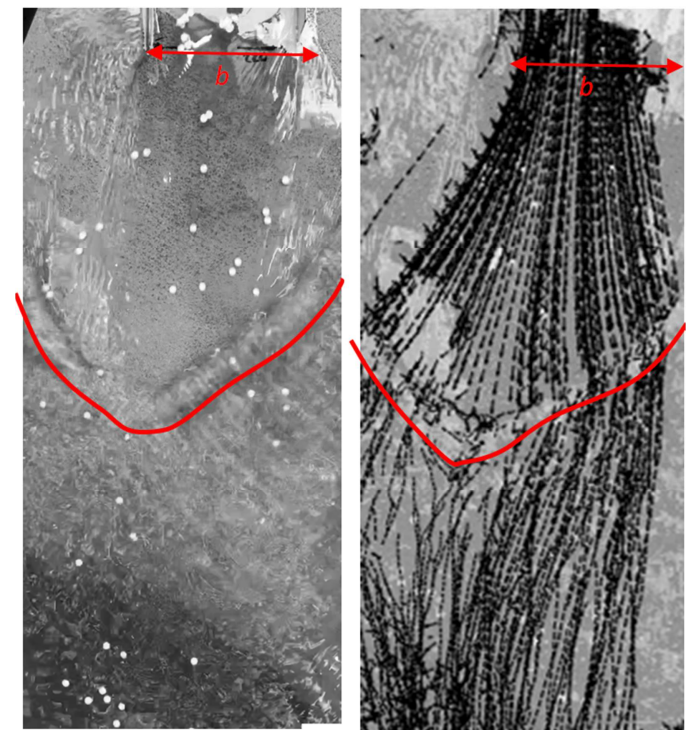

Figure 13. Particle image and local velocities measured with PTV downstream of the outlet of the attraction flow channel with configuration 3 with $b=11 \mathrm{~m}, Q_{T}=530 \mathrm{~m}^{3} / \mathrm{s}, Q_{A}=50 \mathrm{~m}^{3} / \mathrm{s}$. The hydraulic jump is indicated with the red line for $H_{C}=0.0 \mathrm{~m}$.
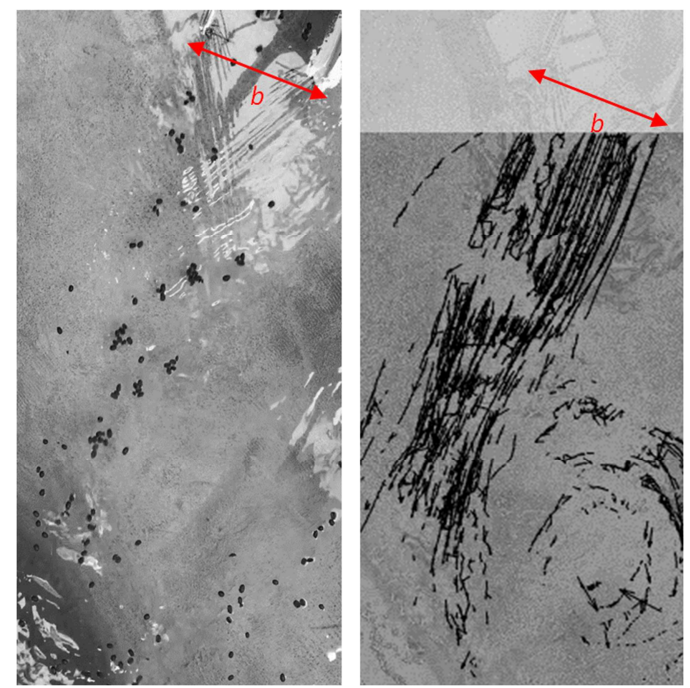

Figure 14. Particle image and local velocities measured with PTV downstream of the outlet of the attraction flow channel with configuration 3 with $b=11 \mathrm{~m}, Q_{T}=530 \mathrm{~m}^{3} / \mathrm{s}, Q_{A}=50 \mathrm{~m}^{3} / \mathrm{s}$. Attraction flow jet without hydraulic jump and the large vortical recirculation zone on the leeward side of the attraction flow for $H_{C}=1.0 \mathrm{~m}$.

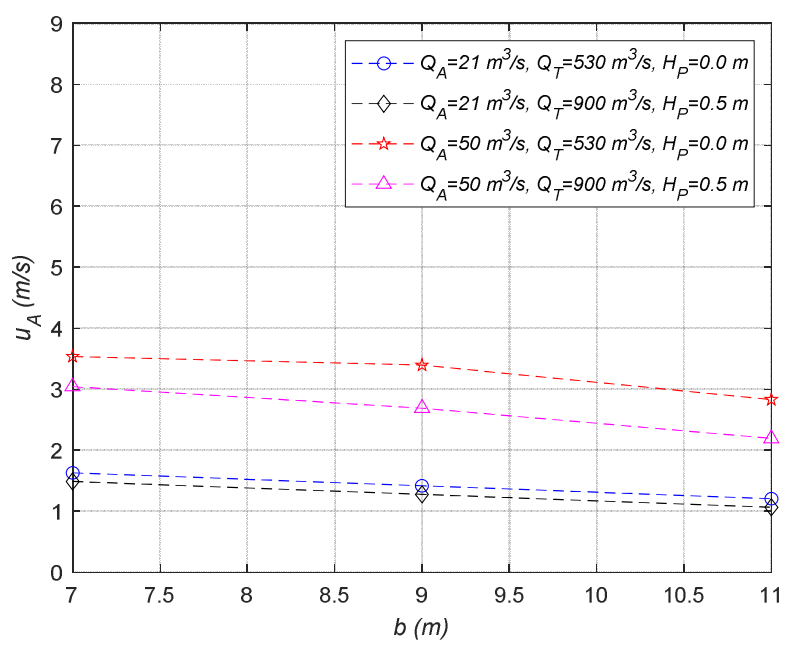

Figure 15. The local velocity at the outlet of the attraction flow channel, $u_{A}$.

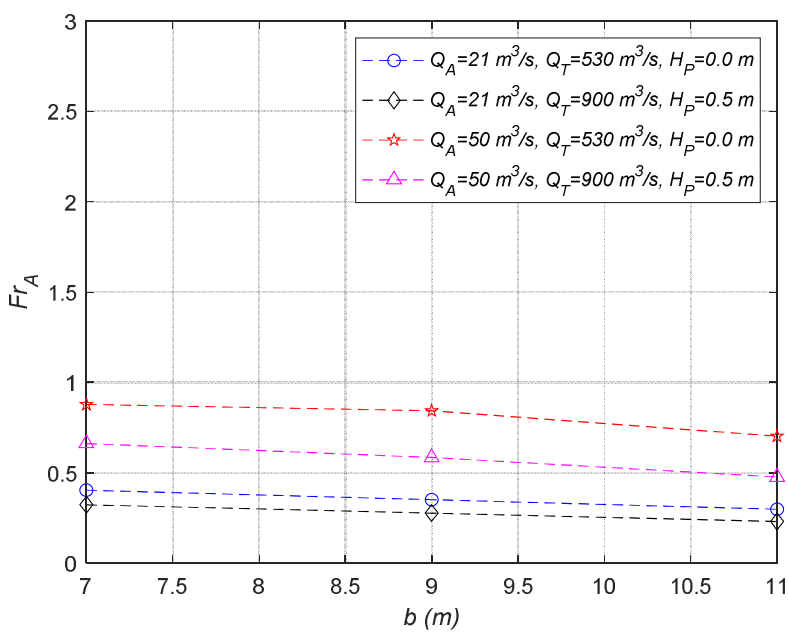

Figure 16. The local $\mathrm{Fr}_{A}$, as a function of the channel outlet width, $b$

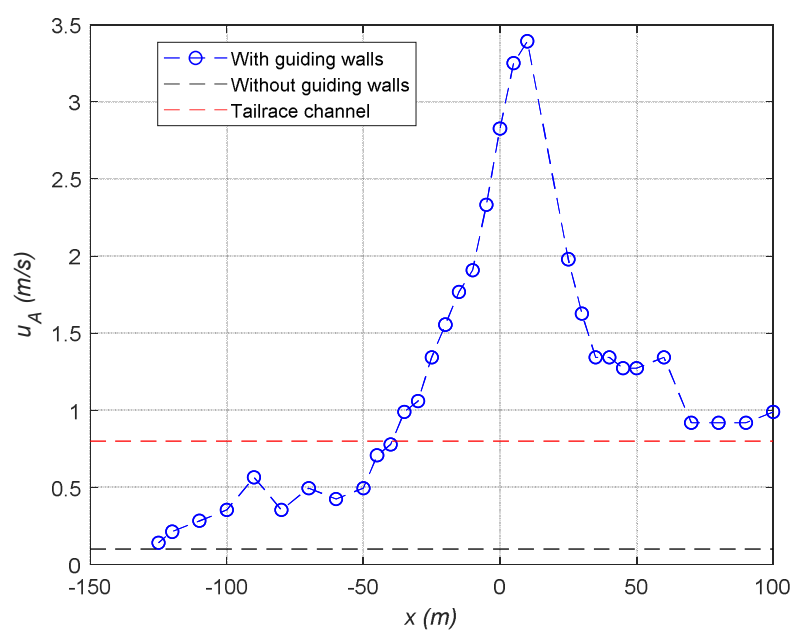

Figure 17. Velocity along the attraction flow channel for configuration 3 for $Q_{T}=530 \mathrm{~m}^{3} / \mathrm{s}, Q_{A}=50 \mathrm{~m}^{3} / \mathrm{s}$ and $H_{C}=0.0 \mathrm{~m}$ and $\mathrm{b}=11 \mathrm{~m} . x=0$ corresponds to the outlet.

Figure 17 shows the velocity along the attraction flow channel and downstream of the outlet along the turbulent jet, measured with the rotameter. Far upstream in the attraction flow channel $(x=130 \mathrm{~m})$ the velocity was like that of the case 
without the guiding walls i.e. $0.1 \mathrm{~m} / \mathrm{s}$ (black dashed line). The velocity slowly increased in the streamwise direction of the channel as the width of the channel successively decreased.

The jet velocity at the outlet was $2.8 \mathrm{~m} / \mathrm{s}$ and just downstream of the outlet it reached its velocity was larger than the surrounding velocity from the hydropower tail race channel until $x=70 \mathrm{~m}$ downstream of the outlet of the attraction flow channel, as is illustrated by the red dashed line corresponding to $0.8 \mathrm{~m} / \mathrm{s}$ in Figure 17 .

\subsection{Boundary Conditions for Dimensioning of the Attraction Flow Channel}

The crest of the wall had to be high enough to contain the maximum flow rate of the attraction flow $50 \mathrm{~m}^{3} / \mathrm{s}$ at a high sea water level but at the same time not be too high in order to be properly overflown at higher flow rates which can occasionally be present in the old river channel, see Table 1. Otherwise there is a risk that the velocity at the outlet of the attraction flow channel can become very high with associated unwanted consequences, e.g. erosion.

\subsubsection{Erosion Risk: Identification of Cases and Locations with High Velocities}

The velocity in and at the outlet of the attraction flow channel increased with the flow rate if the guiding walls were not overflown. This held for lower flow rates, see Figure 18. For higher flow rates and the associated higher water levels, when most of the water flowed over the wall, the velocity at the outlet of the attraction flow channel decreased. It had a maximum around a flow rate of about $1000 \mathrm{~m}^{3} / \mathrm{s}$. This was quite well-correlated with the difference in water level between that upstream of the guiding walls $\left(H_{3}\right)$ and that in the confluence area downstream, $H_{C}$. The velocity at the outlet of the contraction was highest when the water level in the confluence area was low and became $6.5 \mathrm{~m} / \mathrm{s}$ at the most when the flow rate was $1000 \mathrm{~m}^{3} / \mathrm{s}$.

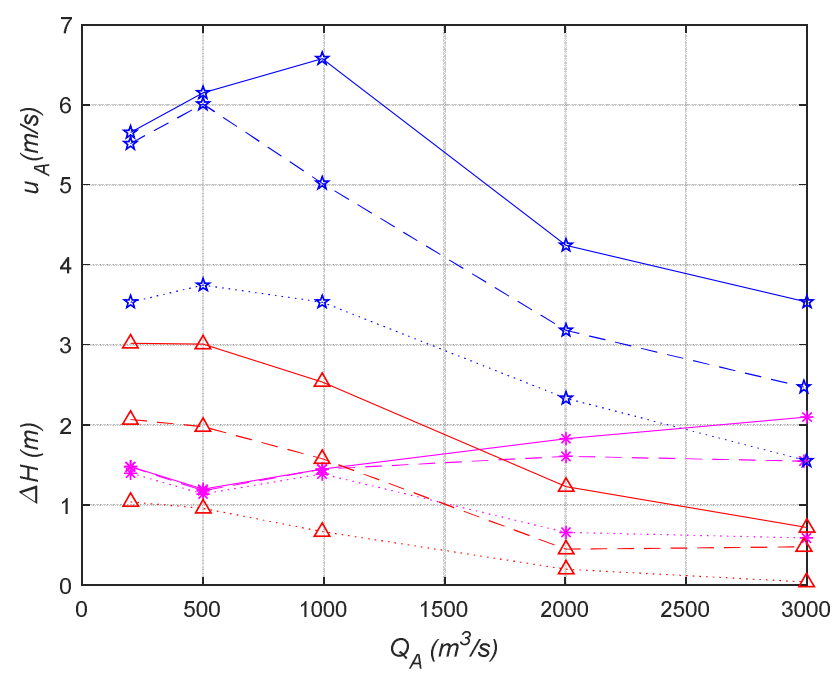

Figure 18. Configuration 2. Velocity at the outlet of the attraction flow channel (blue) as a function of the flow rate in the old river channel $Q_{A}\left(\mathrm{~m}^{3} / \mathrm{s}\right)$. Difference in water level over the inner (red) and over the outer wall (purple). (-) low, (--) nominal and (....) high water level.
The local velocity right downstream of the part of the wall which is normal to the flow also reached about $6.5 \mathrm{~m} / \mathrm{s}$ when the flow was accelerated over the wall and a hydraulic jump was formed just downstream of the guiding wall. This occurred for the highest flow rate, $3000 \mathrm{~m}^{3} / \mathrm{s}$, in combination with the lowest water level.

\subsubsection{Pressure Loads on the Guiding Walls: Difference in Water Level over the Walls}

The measured difference in water level over the inner wall close to the cape $\Delta H=H_{3}-H_{C}(\mathrm{~m})$ is shown in Figure 18. At $200-500 \mathrm{~m}^{3} / \mathrm{s}$, it reaches about $3 \mathrm{~m}$. This is since the wall itself is highest at this location since the river bottom is at a lower position close to the main channel.

The maximum difference in water level over the part of the outer wall $\Delta H=H_{4}-H_{C}(\mathrm{~m})$ which is normal to the flow was also measured. Above $500 \mathrm{~m}^{3} / \mathrm{s}$ it increases with increasing flow rate and becomes slightly more than $2 \mathrm{~m}$ at a flow rate of $3000 \mathrm{~m}^{3} / \mathrm{s}$ for the case of a low water level, $H_{C}$, as is shown in Figure 18.

\section{Discussion}

Heneka et al [22] shows that it is a very complex matter how to introduce an attraction flow properly and that there are no unique answers. However, Wolter [42] analyzed 193 studies evaluating fish-passes designed to provide upstream migration and derived a power model of design discharge needs in relation to river discharge, which is inversely related to river size. In large rivers, a rather small share of mean discharge is sufficient, whereas in small rivers, it cannot be further downscaled due to dimensions. The findings presented provided some guidance for determining the flow-ratio of fish passes at about $5 \%$ of the mean flow of the river, with higher proportions in smaller rivers and vice versa. $5 \%$ in the present case corresponds to about $22 \mathrm{~m}^{3} / \mathrm{s}$.

The attraction flow velocity from the old river channel in this case study was shown to be very small, $0.1 \mathrm{~m} / \mathrm{s}$, compared to the competing velocity from the tailrace channel, which is $0.8 \mathrm{~m} / \mathrm{s}$. Clearly, the attraction flow velocity needs to be increased for a better fish attraction, and thereby increased upstream migration of anadromous species.

The attraction flow channel that was deigned generates a turbulent jet with characteristic large scale vortical structures due to the entrainment of the surrounding water and the velocity gradient on the boundary to the flow from the tailrace channel. These features are attractive for the fish. The goal was an attraction flow jet which should have enough momentum in order to reach out and penetrate well into the confluence area. This was achieved, as was illustrated by Figure 11a. The dashed line in Figure 9b illustrates the approximate mean position of the attraction flow jet based on measurements with the infra-red camera, see Figure 12.

The attraction flow velocity was larger than the surrounding velocity from the hydropower tailrace channel until about $70 \mathrm{~m}$ downstream of the attraction flow channel outlet, see Figure 17. It can be seen in Figure 9b that the 
attraction flow jet crosses the region where the fish spend most of its time in the confluence area. This attraction flow solution required two guiding walls, which also allowed one to direct the jet in a more optimal angle with respect to the flow from the tailrace channel.

At the outlet of the attraction flow channel for configuration 2 the local water depth is $1.65 \mathrm{~m}$ when the water level was $H_{C}=0.0 \mathrm{~m}$. At the position where most of the fish are situated according to Figure 9, i.e. about $30 \mathrm{~m}$ downstream of the attraction flow channel outlet, the local water depth has increased to about 4-5 m, see Figure 4. After that the depth increase rapidly to about $8-9 \mathrm{~m}$ in the main channel. Based on the results for the fish preferred depth positions between $0-4 \mathrm{~m}$, Figure 8 , in combination with the local bathymetry at the channel outlet, it is likely that most fish will be able to detect the attraction jet, rather than swimming beneath it.

Another finding that strengthens this conclusion is that in the telemetry studies, more than $90 \%$ of the tagged salmon were recorded in the rapid just upstream the confluence area, see Lundqvist et al. [30]. However, at that time the rapid was difficult for the salmon to pass and many returned downstream when the spill flow decreased to $20 \mathrm{~m}^{3} / \mathrm{s}$. Since then a deep pool have been constructed at the rapid to reduce "fallbacks" during low flows, and a large pool like fishway has been integrated into the rocks in the difficult passage of the rapid. The conclusion is therefore that an attraction channel based on configuration 2 should successfully guide the salmon up in the bypass channel, and hopefully with a much shorter delay in the migration compared to without the attraction channel.

To place the part of the outer wall, which is normal to the flow, as far downstream as possible also made it possible to avoid any unwanted hydraulic jumps further up in a longer and more narrow attraction flow channel as was the case for configuration 1 .

The goal was set to a velocity in the range $2-3 \mathrm{~m} / \mathrm{s}$ at the outlet of the attraction flow channel. That was accomplished by varying and optimizing the channel width to $b=11 \mathrm{~m}$, which rendered a velocity at the outlet of the attraction flow of $u_{A}=1.2 \mathrm{~m} / \mathrm{s}$ for the case of a flow rate of $21 \mathrm{~m}^{3} / \mathrm{s}$ and a velocity $u_{A}=2.8 \mathrm{~m} / \mathrm{s}$ for the case of $50 \mathrm{~m}^{3} / \mathrm{s}$, Figure 15 .

Across the outlet of the attraction flow channel the velocity varied from about $u_{A}=2 \mathrm{~m} / \mathrm{s}$ closest to the inner guiding wall to over $u_{A}=3 \mathrm{~m} / \mathrm{s}$ close to the outer guiding wall. The length of the channel is two channel widths $(L=2 b=22$ $\mathrm{m})$, see Figure 8 , hence the time $(\mathrm{t})$ needed to pass the channel would be equal to $t=2 \mathrm{~b} /\left(u_{f i s h}-u_{A}\right)$. This results in a time span of $t=11-22 \mathrm{~s}$ for a fish of length $0.5 \mathrm{~m}$ swimming at $u_{f i s h}=4 \mathrm{~m} / \mathrm{s}$ at a temperature of $18^{\circ} \mathrm{C}$, which is within the capacity range of the smallest migrants in the system, Larinier [26].

A secondary aim was to have a Froude number based on $u_{A}$ and the local water depth at the outlet of the attraction flow channel, which is rather high, about $F r_{A} \approx 0.7$, in order to get a flow which starts to become streaming. However, $F r_{A}$ should optimally be less than unity otherwise a supercritical flow will develop, causing excessive dissipation of the jet once the hydraulic jump develops. The results showed that the velocity and water depth rendered a Fr which was optimal for a contraction width of about $b=11 \mathrm{~m}$ for configuration 2 , see Figure 16. However, for configuration 3 , the local bathymetry and associated shallow water depth downstream of the outlet was such that a weak hydraulic jump was generated a bit downstream of the entrance to the attraction flow channel, see Figure 14. Judging from the pattern and similarity of the particle traces in the bulk of the attraction flow the turbulence level is low upstream of the hydraulic jump. However, after the hydraulic jump the trajectories are more randomly distributed as it generates both turbulence, sound and the entrainment of air. The increased level of turbulence can also be seen if one looks carefully in the result from the temperature measurement using the infrared camera, see the rms in Figure 12c. These features have the potential to enhance attraction however, there is also a possibility to remove the locally shallow area if choosing configuration 3 in order to avoid the hydraulic jump.

For rare occasions of high spill flow rates in the old river channel and the associated high velocities, the ability for the fish to pass will be negatively affected since the velocity almost exceeds the burst speed of the fish, $8 \mathrm{~m} / \mathrm{s}$, Calles [11]. However, at such occasions the guiding walls were over flown so fish could also pass over them at other positions, where the velocity was slightly lower.

A risk of erosion occurs when the velocity close to the bottom surface gives a wall shear-stress that overcomes the friction force between the material and the bottom, given the size, angularity and density of the material. The bottom structure was shown from the sonar measurements of the bathymetry to consist of finer material e.g. sand around the outlet of the proposed attraction flow channel with configuration 2. Using (1) for erosion protection design with the highest measured velocity, $u_{\text {mean }}=6.5 \mathrm{~m} / \mathrm{s}$, from Figure 18 , the result becomes $\beta_{50}=10 \mathrm{~m}$. That is so large that a man made, e.g. concrete or steel, structure of the attraction flow channel is the only feasible option in the prototype. However, keep in mind that the design is based on the rare occasions of high spill flow rates in the old river channel.

Results from the tests with and without the guiding walls show no difference in terms of the water level in the confluence area for the same flow rates and positioning of the flap gate at outlet of the model. This implies that the guiding walls of the attraction flow channel designed here will not have any negative effect on the production in the hydropower plant since the design flow rate was also unchanged.

Finally, configuration 2 allowed for the shortest possible guiding wall simplifying the construction process. The total length of the guiding walls becomes about $800 \mathrm{~m}$.

Note: if the wall is built in the prototype a small opening should be included in the part of the wall which is normal to the flow to ensure that the water behind the wall has a certain circulation. That has not been modelled in the tests here since its impact on the hydraulics and loads is negligible. 


\section{Conclusions}

Rather than attempting to improve attraction flow by increasing discharge, which would have negative consequences on hydroelectric production capacity, it is suggested to constrict the width of the entrance of the old river channel leading to the fish ladder in order to increase flow velocity, and therefore hopefully improve the attraction for fish.

The construction cost of such a solution should be evaluated against those involved in increasing discharge as a mean of augmenting attraction for fish.

Measurements were performed tracing tagged fish in the confluence area to understand their movement patterns and behavior.

Based on the fish test results a 1:50 physical scale model was constructed where it was shown that it is hydraulically feasible to improve the attraction flow in the present case study by proper design of guiding walls, which form a contraction, accelerate the attraction flow, while keeping the flow rate unchanged, and form a concentrated jet with a high velocity.

At the same time the higher velocity of the attraction flow was directed towards the area of the confluence where the largest number of fish has been monitored from the telemetry study.

The jet penetrates out to the middle of the tailrace channel in the confluence area and has the potential to attract the upstream migrating fish in a better manner than today.

The results from scaled physical model tests of the present case study were shown to be able to be scaled up to prototype conditions and the main strategy can presumably be generalized to similar flow situations, which exist at other hydropower plants allowing for improved upstream fish migration in coexistence with a sound hydropower production where the production is not affected.

\section{Acknowledgements}

The engineering research was supported by the internal funds at Vattenfall AB, Research R\&D Laboratories. The fish positioning study was financed by Vattenfall Vattenkraft $\mathrm{AB}$, and by ECOHAB: Energiforsk project VKH12400 with money from HOPE and the Swedish Energy Agency's Håva program no. 46430-1 (dnr 2018-003967).

\section{References}

[1] Andersson, A. G., Leonardsson, K., Lindberg, D. E., Lundström, T., Hellström, J. G. I., \& Lundqvist, H. 2016. Describing fish passage in a river confluence with telemetry and CFD. In $11^{\text {th }}$ International Symposium on Eco-hydraulics, Melbourne, Australia.

[2] Angele, K., Andersson, A. Validation of a HEC-RAS model of the Stornorrfors fish migration old river channel against new field data, 2018. $12^{\text {th }}$ ISE 2018, Tokyo, Japan.

[3] Angele, K., Billstein, M. Fish ladder effectivization:
Reconstruction of the Stornorrfors B-spillway, 2018. 12th ISE 2018, Tokyo, Japan.

[4] Angele, K., Odemark, Y., Cehlin, M. Hemström, B., Högström, C. M., Henriksson, M., Tinoco, H., Lindqvist, H., 2011. Flow mixing inside a control-rod guide tube - Experimental tests and CFD simulations. Nuclear Engineering and Design 241 (2011) 4803-4812.

[5] Armstrong, G. S., M. W. Aprahamian, G. A. Fewings, P. J. Gough, N. A. Reader \& P. V. Varallo, 2010, Environment Agency Fish Pass Manual: Guidance Notes On The Legislation, Selection and Approval of Fish Passes In England and Wales, Document - GEHO 0910 BTBP-E-E, Environment Agency, Bristol, U.K.

[6] Baktoft, H., K. O. Gjelland, F. Okland, and U. H. Thygesen. 2017. Positioning of aquatic animals based on time-of-arrival and random walk models using YAPS (Yet Another Positioning Solver). Scientific Reports 7.

[7] Balk, H., and Lindem, T., 2004. Sonar4 and Sonar 5-Pro, Post processing system, Operator Manual v5.9.3. Lindem Data Acquisition, Norway.

[8] Beach, M. H., 1984. Fish pass design - criteria for the design and approval of fish passes and other structures to facilitate the passage of migratory fish in rivers. Ministry of Agriculture, Fisheries and Food, Lowestoft, Fish. Res. Tech. Rep. 78, 45 p.

[9] Braillard, O., Howard, R., Angele, K. Shams, A., Edh, N. Thermal mixing in a T-junction: Novel CFD-grade measurements of the fluctuating temperature in the solid wall. Nuclear Engineering and Design 330 (2018) 377-390.

[10] Burman, A. J., Andersson, A. G., Hellström, J. G. I., and Angele, K.. Case Study of Transient Dynamics in a Bypass Reach. Water 2020, 12, 1585; doi: 10.3390/w12061585.

[11] Calles, O., E. Degerman, H. Wickström, J. Christiansson, S. Gustafsson \& I. Näslund, 2013, Anordningar för upp- och nedströmspassage av fisk vid vattenanläggningar - Underlag till vägledning om lämpliga försiktighetsmått och bästa möjliga teknik för vattenkraft, Rapport 2013: 14, Havs- och vattenmyndigheten.

[12] Calles, E. O. \& L. A. Greenberg, 2009. Connectivity is a two-way street: the need for a holistic approach to fish passage problems in regulated rivers. Rivers research and application 25: $1268-1286$.

[13] Carling, P. A., 1983. Threshold of coarse sediment transport in broad and narrow natural streams. Earth Surface Processes and Landforms, Volume 8, Issue 1.

[14] Castro-Santos T., 2005. Optimal swim speeds for traversing velocity barriers: an analysis of volitional high-speed swimming behavior of migratory fishes. The Journal of Experimental Biology 208, 421-432.

[15] Donaldson, M. R., Hinch, S. G., Suski, C. D., Fisk, A., Heupel, M. R., Cooke, S. J., 2014. Making connections in aquatic ecosystems with acoustic telemetry monitoring. Front. Ecol. Environ. 12, 565-573.

[16] DWA, 2014, Fischaufstiegsanlagen und fischpassierbare Bauwerke - Gestaltung, Bemessung, Qualitätssicherung, DWA Regelwerk, Merkblatt DWA-M 509, Hennef, Germany. 
[17] DVWK, 2002, Fish passes - Design, dimensions and monitoring, Deutscher Verband für Wasserwirtschaft und Kulturbaue. V. (DVWK): translated by Food and Agriculture Organization of the United Nations (FAO), FAO, Rome.

[18] Edlund, L. E., 1996. Norrländsk uppslagsbok: ett uppslagsverk på vetenskaplig grund om den norrländska regionen. [Region-Övre]. "Band 4". Tore Frängsmyr. Umeå: Norrlands universitetsförlag. sid. 309f. Libris länk. ISBN 91-972484-2-8.

[19] Forssén, Å., 2020, Stornorrfors hatchery, Vattenfall (private communication).

[20] Guideline Upstream Fishways on German Federal Waterways (AH FAA), Bundesanstalt für Wasserbau (BAW) und Bundesanstalt für Gewässerkunde (BfG), Version 2.0, 26/06/2015

[21] Hemström, B. 2010, Fiskvandring förbi Stornorrfors kraftverk, 3D-beräkning av lockvattenströmning i älvfåra med ledarm 2010. U10: 13, 1-61.

[22] Heneka, P.; Zinkhahn, M.; Schütz, C.; Weichert, R. B. A Parametric Approach for Determining Fishway Attraction Flow at Hydropower Dams. Water 2021, 13, 743. https://doi.org/10.3390/w13050743.

[23] Katopidis, C. \& R. Gervais, 2016. Fish swimming performance database and analysis, Canadian Science Advisory Secretariat (CSAS), Research document 2016/002, Central and Artic Region, Fisheries and Oceans Canada.

[24] Lantmäteriet, 2020.

https://www.lantmateriet.se/sv/Kartor-och-geografisk-informa tion/Kartor/.

[25] Larinier, M. (1992) Guide pour la conception de dispositifs de franchissement de barrages ou d'obstacles pour les poissons migrateurs. Bulletin Français de la Pêche et de la Pisciculture, 326/327, 1-206.

[26] Larinier, M. (2002). Chapter 3 Biological Factors To Be Taken Into Account in the Design of Fishways, Bull. Fr. Pêche Piscic., 364 suppl. (L), 28-38. https://doi.org/10.1051/kmae/2002105.

[27] Liedtke, T., Rub, M., 2012. Techniques for telemetry transmitter attachment and evaluation of transmitter effects on fish performance. In: Telemetry Techniques: A User Guide for Fisheries Research., pp. 45-87.

[28] Lilja, J., Marjomäki, T. J., Riikonen, R., and Jurvelius, J., 2000. Simulation and experimental measurement of side-aspect target strength of Atlantic salmon (Salmo salar) at high frequency. Can. J. Fish. Aquat. Sci. 61, 2227-2236.

[29] Lindberg, D. E., Leonardsson, K., Andersson, A. G., Lundström, T. S., Lundqvist, H., 2013. Methods for locating the proper position of a planned fishway entrance near a hydropower tailrace. Limnologica 43 (2013) 339-347.
[30] Lundqvist, H., Rivinoja, P., Leonardsson, K. and McKinnell, S., 2008, Upstream passage problems for wild Atlantic salmon (Salmo salar L.) in a flow controlled river and its effect on the population, Hydrobiologia Vol. 602, 111-127.

[31] Pavlov, D. S., 1989, Structures assisting the migrations of non-salmonid fish: USSR, translated by Food and Agriculture Organization of the United Nations, FAO Fisheries Technical Paper, No. 308, Rome.

[32] Peakall, J., Warburton, J., 1996. Surface tension in small hydraulic river models - the significance of the Weber number. Journal of Hydrology (New Zealand). Vol. 35, No. 2, THEME ISSUE: Hydraulic Modelling of braided Gravel-bed Rivers, pp. 199-212.

[33] Peake, S. \& R. S. McKinley, 1998, The re-examination of swimming performance relative to downstream migration of juvenile salmonids. Can J Fish Aquat Sci 55: 682-687.

[34] Pincock, D. G., Johnston, S. V., 2012. Acoustic telemetry overview. Telemetry techniques: a user guide for fisheries research, pp. 305-337.

[35] Sektionen för Geoteknik. Erosionsskydd i vatten vid väg- och brobyggnad, 1978, Vägverket, 1987: 18, 1-30.

[36] Smith, B. L., Mahaffy, J. H., Angele, K., A CFD benchmarking exercise based on flow mixing in a T-junction. Nuclear Engineering and Design 264 (2013) 80-88.

[37] Sveen, J. K., An introduction to MatPIV v. 1.6.1, eprint series, Dept. of Math. University of Oslo, "Mechanics and Applied Mathematics", NO. 2 ISSN 0809-4403, August 2004.

[38] Thorstad, E. B., Fiske, P., Aarestrup, K., Hvidsten, N. A., Hårsaker, K., Heggberget, T. G. and Økland, F. Upstream migration of Atlantic salmon in three regulated rivers. Aquatic telemetry: Advances and applications. Proceedings of the Fifth Conference on Fish Telemetry held in Europe. Ustica, Italy, 9-13 June 2003. Rome, FAO/COISPA. 2005. 295p.

[39] USFWS (U.S. Fish and Wildlife Service). 2019. Fish Passage Engineering Design Criteria. USFWS, Northeast Region R5, Hadley, Massachusetts.

[40] Widén, Å., R. Jansson, M. Johansson, M. Lindström, L. Sandin \& D. Wisaeus, 2016, Maximal Ekologisk Potential i Umeälven, www.umealven.se.

[41] Wolfram Research, Inc. 2019. Mathematica, Version 12.0, Champaign, IL.

[42] Wolter, C., Schomaker, C. Fish passes design discharge requirements for successful operation. River Res Applic. 2019; $1-5$. 